\title{
A Comparative Study of Physical Fitness among Egyptian and German Children Aged Between 6 and 10 Years
}

\author{
Osama Abdel Karim1,2, Achraf Ammar1,3, Hamdi Chtourou3,4, Matthias Wagner5, \\ Lars Schlenker6, Anthony Parish', Tarek Gaber ${ }^{2}$, Anita Hökelmann'1, Klaus Bös6 \\ ${ }^{1}$ Institute of Sport Science, Otto-von-Guericke-University Magdeburg, Magdeburg, Germany \\ ${ }^{2}$ Faculty of Physical Education, Assiut University, Assiut, Egypt \\ ${ }^{3}$ Research Unit (EM2S), High Institute of Sport and Physical Education, Sfax University, Sfax, Tunisia \\ ${ }^{4}$ Research Laboratory "Sport Performance Optimization" National Center of Medicine and Sciences in Sport \\ (CNMSS), Tunis, Tunisia \\ ${ }^{5}$ Institute of Sports Science, University of Konstanz, Konstanz, Germany \\ ${ }^{6}$ Institute of Sport and Sports Science, University of Karlsruhe, Karlsruhe, Germany \\ ${ }^{7}$ Adolescent and Adult Education Sports Center, Armstrong State University, Savannah, USA \\ Email: osama.karim@ovgu.de, ammar.achraf@ymail.com, $\underline{h}$ chtourou@yahoo.fr, \\ matthias.wagner@uni-konstanz.de, Lars.schlenker@kit.de, anthony.parish@armstrong.edu, \\ tgaber98@yahoo.com, anita.hoekelmann@ovgu.de, klaus.boes@kit.de
}

Received 6 January 2015; accepted 24 January 2015; published 27 January 2015

Copyright (C) 2015 by authors and Scientific Research Publishing Inc.

This work is licensed under the Creative Commons Attribution International License (CC BY).

http://creativecommons.org/licenses/by/4.0/

cc) (i)

Open Access

\section{Abstract}

The aim of the present study was to compare the physical fitness of Egyptian $(n=403)$ and German $(n=1712)$ volunteer children aged between 6 and 10 years. The German motor test (DMT), height, weight, and body mass index (BMI) were measured. ANOVA showed that the results of the motor performance ability (MPA) were affected by the ethnicity with higher performance for German children $(p<0.05)$. German children's superiority in strength is present from the age of 6 years ( $p<0.001$ for the Push-Ups and $p<0.05$ for the Long Jumping), to the age of 10 years ( $p<$ 0.001 and $p<0.01$, respectively). However, their superiority in coordination ability was observed only in school aged children ( $p<0.05$ and $p>0.05$, respect to 6 and 10 years old). With maturation from six to ten years, the achievement level for both populations show a positive improvement in the coordination and strength, and reduction in the flexibility $(p<0.001)$, with a higher rate of increase for the German children, except boys in the Push-Ups. Therefore, more strength-oriented physical activities before the age of 6 years and coordination-oriented activities between 6 and 8 years are recommended for Egyptian PE curriculum. 
Keywords

Motor Development, Physical Fitness, Anthropometric Parameters, PE Curriculum

\section{Introduction}

Current research has established that a lack of exercise and a sedentary lifestyle plays a central role in many health problems. Increasing physical and motor activities have been shown to positively influence the achievement level of motor development, which in turn positively influences the general development of children (Kambas et al., 2004; Ketelhut et al., 2005; Krombholz, 2005; Kunz, 1993; Rethorst, 2004). In this context, taking the motor performance ability (MPA) as an evident indicator of the children's physical fitness and motor development level, Booth et al. (1997) shows that children who have better MPA are more physically active and less likely to be sedentary than those with poorer MPA. They also suggest that potential MPA to target in children should include activities, such as running, speed, agility, jumping, balance, and visual motor skills.

Likewise, the interactive effects between MPA and health development, as well as possible genetic differences, have become some of the most important scientific fields to define the expected disease which may be related to later growth and development (Gallahue \& Ozmun, 2006). The link between MPA, health and growth development has only been researched and observed in developed countries (i.e. studies by Kuntzleman et al. (1992) in USA, Craig et al. (1994) in Canada, Booth et al. (1997) and Tomkinson (2004) in Australia, and Bös \& Scheid (1994) and Bös (2003) in Germany). Recently, this link was affirmed and well established in the study conducted by Stodden et al. (2008).

In Egypt the majority of related studies have concentrated on studying physical activities and health (Alwasif, 2001), but not how it relates to MPA. Hassan (2003) evaluated the conditional abilities by the talented children. In another study, Elbatrawy (2008) looked at the development of MPA of children with mental disability during free time activities. Studies that focused on the level of MPA by typically developed children at primary school age have rarely been implemented in the Egyptian environment (Abdel Karim, 2013). Therefore, given the lack of studies in this field in Egypt and based on the idea of Kelly (2010) who believes that addressing the physical and motor needs of children (regarding age and gender factors) is one of the most important requirements for the development of PE curriculum, the first objective of the present study was to evaluate the anthropometric parameters (i.e. Height, Weight and BMI) and the MPA (i.e. coordination, strength and flexibility) of Egyptian children (i.e. boys and girls) aged from 6 to 10 years old.

Additionally, although as a general rule the stages of motor development are the same for all children worldwide, there are developmental differences in the rate of motor development dependent on the special characteristics of the environmental conditions in which children grow (Barros et al., 2003; Giagazoglou et al., 2007). Comparative studies are implemented to improve knowledge and recognize and identify differences in order to learn from other orientations and suggest solutions (OECD, 2001). Despite the evidence showing a need for cross cultural fitness studies, Germany has been involved in only a limited number of these studies (Wagner et al., 2009).

Supported by previous studies, researchers from the present study believe that comparing fitness development between German and Egyptian children should be considered. The presented comparison could be a step forward in developing a primary level PE curriculum for both countries. Additionally, this comparison could be used to compare with the results of a similar study by Hardman (2009), who defined differences between Middle East and European countries in achieving gender equality in PE (i.e. 33\% and 94\%, respectively). The second objective of this study is to measure the difference of anthropometric parameters and MPA among children of primary school in Egypt and Germany according to age (6 - 10 years old) and gender. It should be noted that the choice of the age period is based on the results of Bös \& Ulmer (2003) who suggest that this age sequence (6 - 10 years old) is very important in the development of the children reaching basic levels of motor development for the age of 9 or 10.

\section{Method}

\subsection{Participants and Setting}

Participants were primary school aged-children ranging in age from 6 to 10 years. The participant pool included 
children from Germany $(\mathrm{n}=1712)$; from the MoMo study (4529 randomly selected children; Bös, 2009; Wagner et al., 2013) and Egypt $(n=403)$. The selection of participating Egyptian schools was based on age, socioeconomic level, and demographic characteristics. Thirteen primary schools representing a lower, medium, and higher socioeconomic status were chosen. According to Helsinki Declaration, participation was voluntary and informed written consent was obtained from the school directors, participants and their parents or guardians before the children entered into the study.

The measurement was carefully supervised inside the school gym by observers trained in anthropometric and motor techniques with respect to the WHO recommendations for the anthropometric tests and to the German Nationwide Survey (KiGGS) for the motor tests. A well-tested design and calibrated equipment at frequent intervals were used.

Height was measured in a standing position, without shoes, to the nearest $0.1 \mathrm{~cm}$ using portable gauges (Seca, Germany). The weight was performed with minimal clothing and recorded to the nearest $0.1 \mathrm{~kg}$ using electronic scales (Teraillon, France). Body mass index (BMI) was calculated using the software of The German motor test (DMT). The DMT was administered in a group setting during regular school classes. The measurements were conducted in sessions lasting about $90 \mathrm{~min}$. Testing sessions included 20 children participants at a time. Five assistant researchers assisted in administering the testing.

\subsection{Test Description}

The German motor test (DMT) is targeted of the children ages of 6 - 18 years (Bös, 2009). This test is used to assess motor abilities including endurance, strength, speed, coordination, and flexibility which are used together to indicate the general MPA (Bös, 1987). Assessing the motor abilities of the DMT is achieved through structured motor skills like running, jumping, and balancing. Sport-specific skills are excluded in this testing. In the current study the test items measuring the coordination (i.e. balancing backwards (BB), jumping sideways (JS)), Strength (i.e. push-ups (PU), long jumping (LJ)) and flexibility (i.e. stand and reach (SR)) were used.

\subsection{Validity and Reliability}

The content-related validity of all tests was evaluated to be reliable with regard to significance and feasibility as based on expert ratings. The test development, used in this study, was based on an international expert questionnaire involving 40 selected fitness experts in 25 European countries who were asked about the relevance of the test contents and requirements in sport-motoric tests regarding the documentation of MPA (Bös, 1992). To determine test-retest reliability for the Egyptian sample, the motor tests were performed twice within 2weeks on the same children, applying the same test situation and the same study investigators. There was a good test-retest reliability coefficients $\left(r_{\min }=0.68\right.$ to $\left.r_{\max }=0.94\right)$.

\subsection{Data Analysis}

All statistical tests were processed using STATISTICA Software (Stat-Soft, France). Following normality confirmation using the Shapiro-Wilks W-test, anthropometric parameters, and motor performance, data were analyzed using a three-way ANOVA ( 2 levels [countries] $\times 2$ levels [gender] $\times 5$ levels [age]). Post hoc tests were conducted when significant main effects were found using Fisher's least significant difference (LSD). Effect sizes were calculated as partial eta-squared $\left(\eta^{2} p\right)$ to assess the practical significance of our findings. Significance was set at $p<0.05$.

\section{Results}

Statistical analysis (Figure 1) showed a significant effect, in regards to countries, for the anthropometric parameters (i.e. Height $\left(\mathrm{F}=4.5, p<0.05, \eta^{2} p=0.14\right)$, Weight $\left(\mathrm{F}=16.88, p<0.001, \eta^{2} p=0.38\right)$ and BMI $(\mathrm{F}=12.5$, $p<0.01, \eta^{2} p=0.32$ ) with higher values of the Height for the German children and higher values of the Weight and BMI for the Egyptian children. Similarly, there was a significant effect in the intra-group differences, with higher values of height $(p<0.05)$ for both German boys and girls compared to their Egyptian peers. Higher values of weight $(p<0.01$ and $p<0.05)$ and BMI $(p<0.001$ and $p<0.05)$ respectively for Egyptian boys and girls compared to their German peers was observed. Concerning the effect of the gender in the anthropometric children's parameters, statistical analysis showed no significant difference between total boys and girls tested in either 


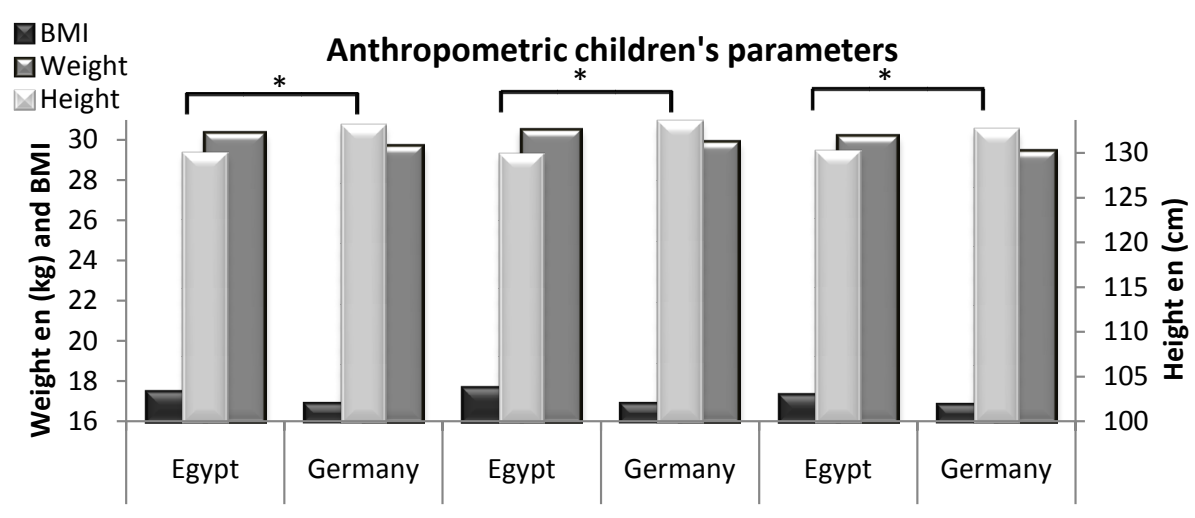

Figure 1. Anthropometric children's parameters among Egyptian and German populations. * represents significant difference between Country in the anthropometric parameters (i.e. Height in $(\mathrm{cm})$, Weight in $(\mathrm{kg})$ and BMI with $p<0.05$. Values are represented as mean $\pm \mathrm{SE}$.

participating country $(p>0.05)$. Additionally for these variables, there were no significant interactions between countries and gender $(p>0.05)$.

Mean values of the different DMT tests among Egyptian and German children are shown in Table 1. Both countries and gender effect were significant $(\mathrm{F}=79.8, p<0.001$ and $\mathrm{F}=20.82, p<0.01$ respectively) with a better performance for the German than the Egyptian children in the majority of tested abilities $(p<0.05$ for JS and SR and $p<0.001$ for LJ and PU) and a better performance for the boys than girls in the strength tests ( $p<$ 0.001 and $p<0.05$ respectively for LJ and PU). However, girls performed better in the BB and SR tests ( $p<$ $0.05)$. Concerning the gender intra-group differences, boys in Egypt have a higher performance than girls in the strength exercises ( $p<0.001$ and $p<0.01$, respectively for LJ and PU tests) and jumping sideways exercise ( $p<$ $0.01)$. However, non-significant difference has been shown for the (BB) and (SR) tests $(p>0.05)$. On the other hand, German girls show better motor performance ability in the majority of tests (i.e. BB, JS and SR with $p<$ $0.05, p<0.05$ and $p<0.01$ respectively). Boys performed better only in the LJ test $(p<0.01)$.

Regarding the countries intra-group differences, German boys and girls show higher MPA than their Egyptian counterparts; (i.e. BB, LJ and PU respectful to boys ( $p<0.05, p<0.001$ and $p<0.05$ respectively), and BB, JS, LJ, PU and SR respectful to girls ( $p<0.01$ for BB, JS and SR and $p<0.001$ for LJ and PU).

An overview of the MPA (Table 1) shows the existence of interaction $(p<0.01)$ between countries and gender $(\mathrm{F}=32.85, \mathrm{~F}=40.19, \mathrm{~F}=28.59$ and $\mathrm{F}=34.95$ for JS, LJ, PU and SR respectively).

Figures 2-4 show the development of the MPA tests among Egyptian and German children (i.e., BB, JS, PU, LJ and SR) from the age of 6 years old to the age of 10 years old. As these figures indicate, all tests were affected by age (with $\mathrm{F}=12.04, p<0.001, \eta^{2} p=0.32 ; \mathrm{F}=67.09, p<0.001, \eta^{2} p=0.74 ; \mathrm{F}=37.95, p<0.001, \eta^{2} p$ $=0.58 ; \mathrm{F}=21.92, p<0.001, \eta^{2} p=0.50$ and $\mathrm{F}=13.09, p<0.001, \eta^{2} p=0.36$ respectively for the BB, JS, LJ, PU and SR).

Concerning the coordination ability (Figure 2), statistical analysis shows that at age 6 Egyptian children had higher performance levels $\left(\mathrm{F}=5.42, p<0.05, \eta^{2} p=0.15\right)$ than German children in the Balance test (i.e. for boys as well as girls $p<0.05$ ). JS test results showed no significant difference at age 10; the performance results were inversed with higher values for the German children in both tests $\left(\mathrm{F}=11.78, p<0.01, \eta^{2} p=0.23\right.$ for the BB test and $\mathrm{F}=4.43, p<0.05, \eta^{2} p=0.10$ for the SJ test. From age 6 to 10 German children (i.e. boys and girls) showed improvement in their coordination abilities in both tests $(p<0.001 ; 55.24 \% \pm 4.11 \%$ and $46.20 \% \pm 4.12 \%$ for BB test and $72.27 \% \pm 7.98 \%$ and $66.95 \% \pm 7.86 \%$ for JS test). However, a significant improvement was registered only for the JS test for Egyptian children $(p<0.001)$, with a lower rate of increase $(p<0.01)$ than their German peers ( $62.92 \pm 7.65$ and $44.44 \% \pm 7.93 \%$ respective to Egyptian children JS test).

A more in depth look, using age 8 as a middle age in our sample, showed a significant improvement for the German samples (i.e. boys and girls) in both the age range before and after the median age (i.e. $6-8$ and $8-10$ years old) in the coordination abilities $(p<0.001)$. The improvement level observed among the German children was not observed for the Egyptian sample in most instances. In fact, no significant improvement was shown during the $6-8$ age period for girls in the BB test and for boys in the JS test. Similarly, no significance was shown during the $8-10$ age period for both gender in BB test and for girls in the JS test $(p>0.05)$. For both 

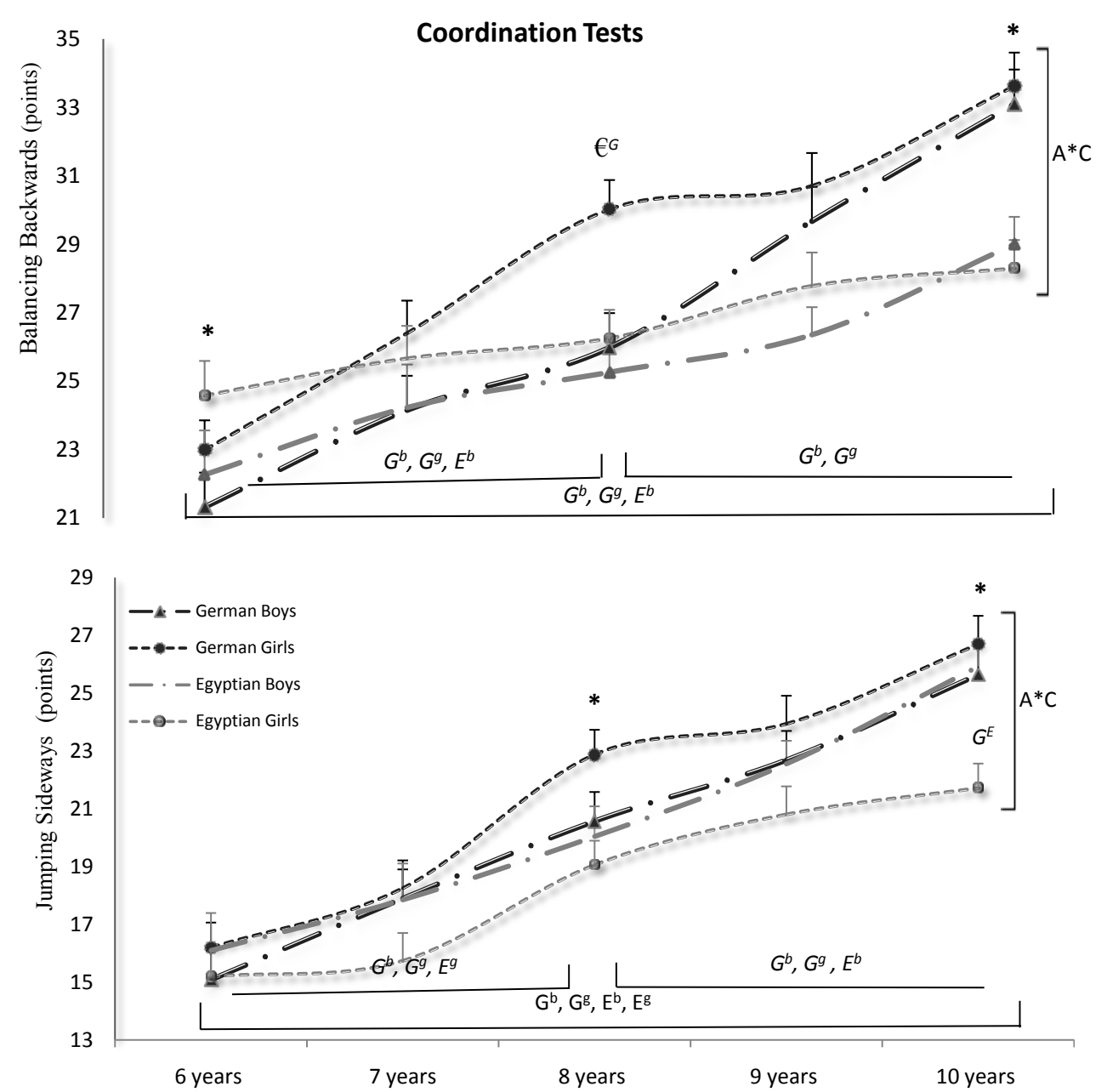

Figure 2. Coordination abilities (i.e. BB and JS) of Egyptian and German boys and girls among different age. $A * C$ indicates significant interaction age $\mathrm{x}$ country with $p<0.001 . €^{\mathrm{G}}$ and $€^{\mathrm{E}}$ indicate significant effect of the Gender respectively in the German and Egyptian children's abilities $(p<0.05)$. * indicates significant effect of the country $(p<0.05) . \mathrm{G}^{\mathrm{b}}, \mathrm{G}^{\mathrm{g}}, \mathrm{E}^{\mathrm{b}}$ and $\mathrm{E}^{\mathrm{g}}$ Indicate significant improvement in the tested ability respect to the German boys and girls and Egyptian boys and girls $(p<0.05)$.

tests of coordination abilities a significant interaction regards to age $\times$ countries was shown $(\mathrm{F}=4.99, p<0.01$, $\eta^{2} p=0.16$ and $\mathrm{F}=5.24, p<0.001$, respectively for $\mathrm{BB}$ and JS).

Regarding strength ability (Figure 3), statistical analysis show that at age 6 German children (i.e., boys and girls) had higher performance in both LJ and PU tests than the Egyptian children ( $\mathrm{F}=18.35, p<0.001, \eta^{2} p=$ 0.37 and $\mathrm{F}=3.54, p<0.05, \eta^{2} p=0.18$, respectively). The exception was for boys in the PU test; the superiority in LJ and PU persist and increase until age of 10 in both tests $(\mathrm{F}=59.18, p<0.001$ and $\mathrm{F}=8.96, p<0.01$, respectively) especially for girls.

Concerning gender difference, the LJ test showed a significant difference for the German population in the 10 year age level $(p<0.01)$ but not at the 6 year age level; while the Egyptian sample showed significant difference from the entire age range $(6-10$ years old $)(p<0.01)$. In the PU test, no significant difference was found between German boys and girls. However, in the Egyptian children, it was present from age $6(p<0.01)$ through age $10(p<0.001)$. Results showed significant improvement of strength performance from age 6 to age 10 ( $p<$ 0.001 ) especially for boys (rates of increase: $25.15 \% \pm 4.50 \%, 21.10 \% \pm 3.36 \%, 28.50 \% \pm 4.11 \%$ and $25.49 \% \pm$ $3.63 \%$ in the $\mathrm{LJ}$ test and $79.34 \% \pm 6.74 \%, 42.12 \% \pm 7.74 \%, 50.73 \% \pm 6.61 \%$ and $38.62 \% \pm 7.73 \%$ in the PU test, respective tor Egyptian boys and girls as well as German boys and girls).

Additionally, from age 6 to 8 no significant improvement was shown for the Egyptian girls in both tests $(p>$ $0.05)$ and similar results were shown for the German girls in the $8-10$ age period. For the LJ test, a significant 

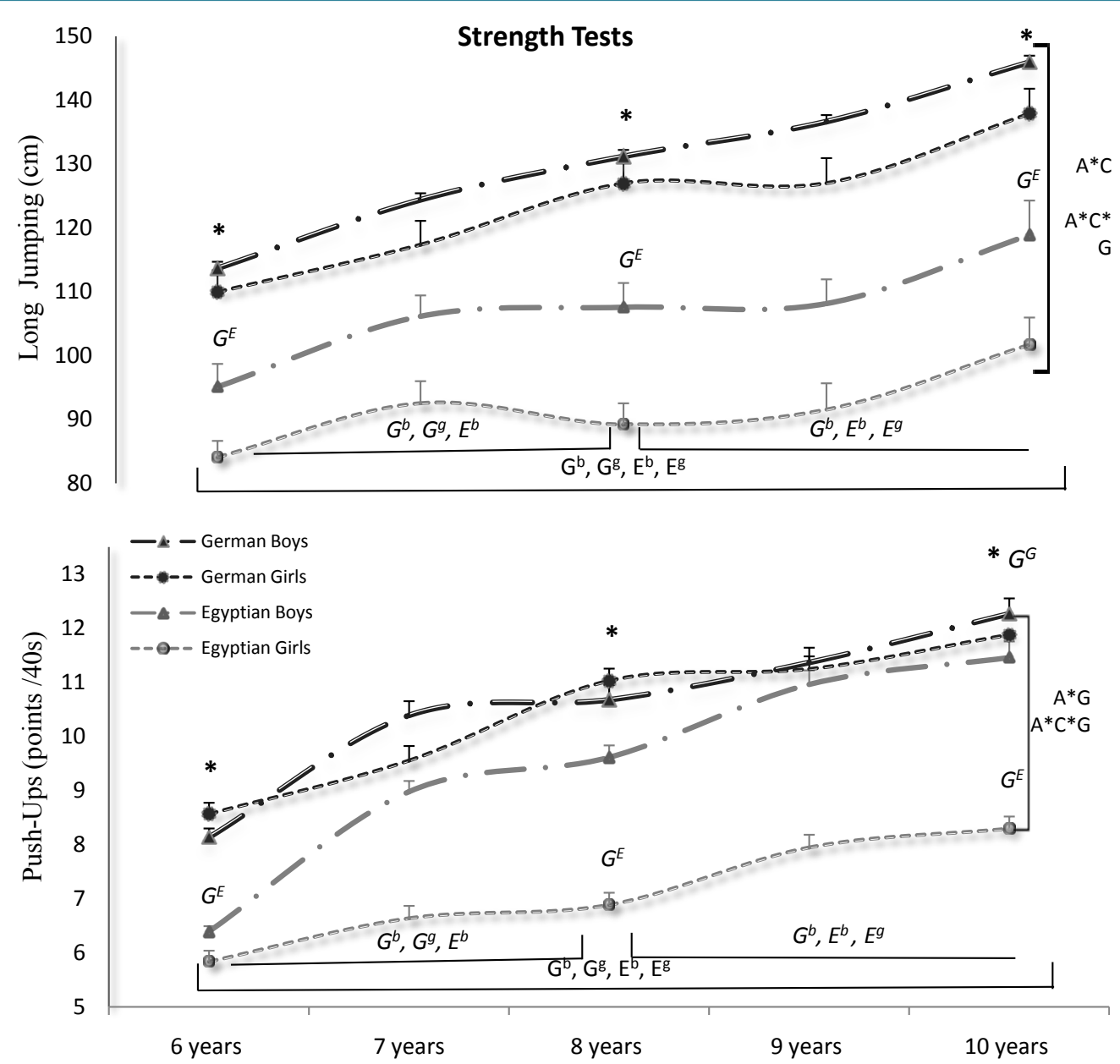

Figure 3. Strength abilities (i.e. LJ and PU) of Egyptian and German boys and girls among different age. $A^{*} \mathrm{C}, A^{*} \mathrm{G}$ and $A^{*} C^{*} \mathrm{G}$ indicate respectively significant interaction age $\times$ country $(p<0.001)$, age $\times$ gender and age $\times$ country $\times$ gender $(p<0.05)$. $€^{\mathrm{G}}$ and $€^{\mathrm{E}}$ indicate significant effect of the Gender respectively in the German and Egyptian children's abilities $(p<0.05)$ * indicates significant effect of the country $(p<0.05) . \mathrm{G}^{\mathrm{b}}, \mathrm{G}^{\mathrm{g}}, \mathrm{E}^{\mathrm{b}}$ and $\mathrm{E}^{\mathrm{g}}$ indicate significant improvement in the tested ability respect to the German boys and girls and Egyptian boys and girls $(p<0.05)$.

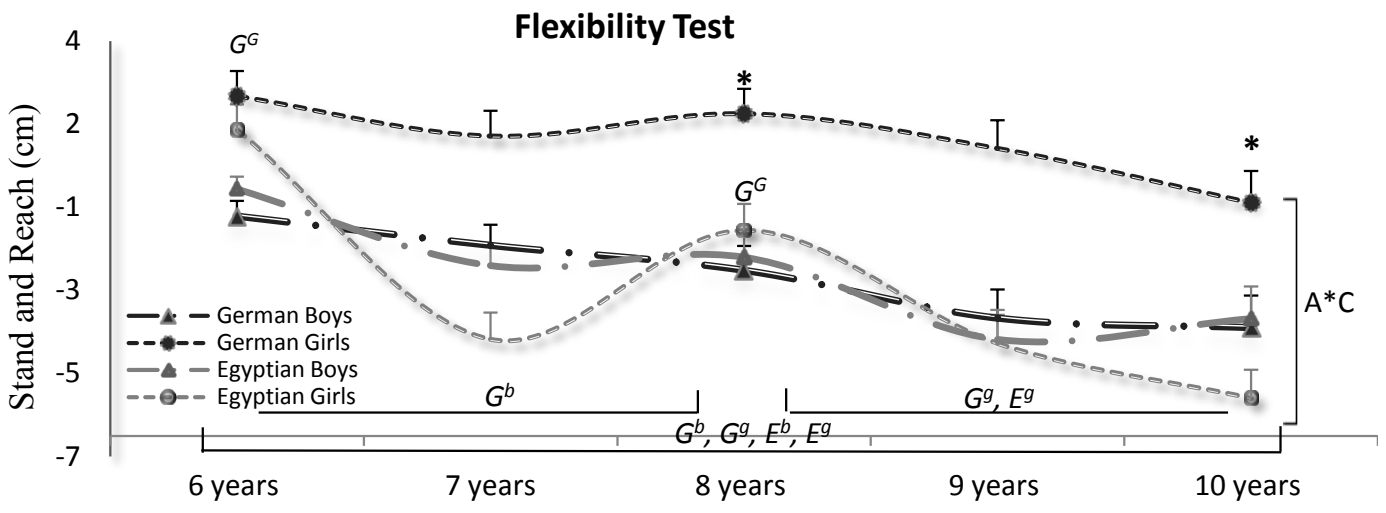

Figure 4. Flexibility abilities (i.e. Stand and Reach) of Egyptian and German boys and girls among different age. $A^{*} \mathrm{C}$ indicates significant interaction age $\times$ country with $p<0.01 . €^{\mathrm{G}}$ and $€^{\mathrm{E}}$ indicate significant effect of the Gender respectively in the German and Egyptian children's abilities $(p<0.05)$. ${ }^{*}$ indicates significant effect of the country $(p<0.05) . \mathrm{G}^{\mathrm{b}}, \mathrm{G}^{\mathrm{g}}, \mathrm{E}^{\mathrm{b}}$ and $\mathrm{E}^{\mathrm{g}}$ indicate significant improvement in the tested ability respect to the German boys and girls and Egyptian boys and girls $(p<0.05)$. 
Table 1. MPA characteristics of Egyptian and German boys and girls (age between 6 and 10 years old).

\begin{tabular}{|c|c|c|c|c|c|c|c|c|c|c|c|}
\hline & \multicolumn{3}{|c|}{ Egypt } & \multicolumn{3}{|c|}{ Germany } & \multicolumn{2}{|c|}{ Egy + Ger } & \multicolumn{3}{|c|}{ ANOVA } \\
\hline 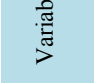 & Boys & Girls & Total & Boys & Girls & Total & Boys & Girls & Country & Gender & Interaction \\
\hline $\begin{array}{c}\text { BB } \\
\text { (points) }\end{array}$ & $25.42^{*} \pm 5.40$ & $26.5^{*} \pm 4.83$ & $25.97 \pm 5.11$ & $26.85^{*} € \pm 4.12$ & $28.76^{*} € \pm 4.10$ & $27.80 \pm 4.11$ & $26.14 € \pm 4.76$ & $27.64 € \pm 4.46$ & $\begin{array}{c}\mathrm{F}_{(1,4)}=3.05 \\
p>0.05 \\
\eta^{2} p=0.43\end{array}$ & $\begin{array}{c}\mathrm{F}_{(1,4)}=11.23 \\
p<0,05 \\
\eta^{2} p=0.74\end{array}$ & $\begin{array}{c}\mathrm{F}_{(1,4)}=1.47 \\
p>0.05 \\
\eta^{2} p=0.27\end{array}$ \\
\hline $\begin{array}{c}\text { JS } \\
\text { (points) }\end{array}$ & $20.00 € \pm 2.56$ & $18.02^{*} € \pm 2.46$ & $19.0^{*} \pm 2.51$ & $19.89 € \pm 2.40$ & $21.10^{*} € \pm 2.40$ & $20.4^{*} \pm 2.40$ & $19.94 \pm 2.48$ & $19.56 \pm 2.43$ & $\begin{array}{c}\mathrm{F}_{(1,4)}=12.69 \\
p<0.05 \\
\eta^{2} p=0.76\end{array}$ & $\begin{array}{c}\mathrm{F}_{(1,4)}=0.98 \\
p>0.05 \\
\eta^{2} p=0.20\end{array}$ & $\begin{array}{c}\mathrm{F}_{(1,4)}=32.85 \\
p<0.01, \eta^{2} p \\
\quad=0.89\end{array}$ \\
\hline $\begin{array}{c}\mathrm{LJ} \\
(\mathrm{cm})\end{array}$ & $106.6^{*} € \pm 8.90$ & $91.3^{*} € \pm 7.84$ & $98.9^{*} \pm 8.37$ & $129.9^{*} € \pm 8.73$ & $123.3^{*} € \pm 8.21$ & $126.6^{*} \pm 8.47$ & $118.2 € \pm 8.82$ & $107.3 € \pm 8.03$ & $\begin{array}{c}\mathrm{F}_{(1,4)}=138.6 \\
p<0.001 \\
\eta^{2} p=0.97\end{array}$ & $\begin{array}{c}\mathrm{F}_{(1,4)}=114.3 \\
p<0.001 \\
\eta^{2} p=0.97\end{array}$ & $\begin{array}{c}\mathrm{F}_{(1,4)}=40.19 \\
p<0.01 \\
\eta^{2} p=0.91\end{array}$ \\
\hline $\begin{array}{c}\text { PU } \\
\text { (pts/40 } \\
\text { s) }\end{array}$ & $9.48^{*} € \pm 1.66$ & $7.13^{*} € \pm 1.45$ & $8.30^{*} \pm 1.56$ & $10.57^{*} \pm 1.48$ & $10.46^{*} \pm 1.47$ & $10.51^{*} \pm 1.48$ & $10.03 € \pm 1.57$ & $8.79 € \pm 1.46$ & $\begin{array}{c}\mathrm{F}_{(1,4)}=347.6 \\
p<0.001 \\
\eta^{2} p=0.99\end{array}$ & $\begin{array}{c}\mathrm{F}_{(1,4)}=16.0 \\
p<0.05 \\
\eta^{2} p=0.80\end{array}$ & $\begin{array}{c}\mathrm{F}_{(1,4)}=28.5 \\
p<0.01 \\
\eta^{2} p=0.88\end{array}$ \\
\hline $\begin{array}{l}\text { SR } \\
(\mathrm{cm})\end{array}$ & $-2.10 \pm 2.58$ & $-2.44^{*} \pm 2.51$ & $-2.28^{*} \pm 2.55$ & $-2.14 € \pm 2.90$ & $1.44^{*} € \pm 2.91$ & $-0.50^{*} \pm 2.90$ & $-2.13 € \pm 2.74$ & $-0.65 € \pm 2.71$ & $\begin{array}{c}\mathrm{F}_{(1,4)}=12.8 \\
p<0.05 \\
\eta^{2} p=0.76\end{array}$ & $\begin{array}{c}\mathrm{F}_{(1,4)}=13.3 \\
p<0.05 \\
\eta^{2} p=0.77\end{array}$ & $\begin{array}{c}\mathrm{F}_{(1,4)}=34.9 \\
p<0.01 \\
\eta^{2} p=0.90\end{array}$ \\
\hline & & & & & & & & & $\begin{array}{c}\mathrm{F}_{(1,4)}=79.8 \\
p<0.001 \\
\eta^{2} p=0.95\end{array}$ & $\begin{array}{c}\mathrm{F}_{(1,4)}=20.8 \\
p<0.01 \\
\eta^{2} p=0.84\end{array}$ & $\begin{array}{c}\mathrm{F}_{(1,4)}=45.4 \\
p<0.01, \eta^{2} p \\
\quad=0.92\end{array}$ \\
\hline
\end{tabular}

The different results of coordination tests ((balancing backwards (BB) and jumping sideways (JS)), strength tests ((push-ups (PU) and long jumping (LJ)) and flexibility test ((stand and reach (SR)) represented as mean \pm SE among boys and girls in Egypt and Germany. Significant differences between country are represented with ${ }^{*}$. Significant differences between gender are represented with " $€$ " $(p<0.05)$.

interaction was found; countries $\times$ age $\left(\mathrm{F}=7.82, p<0.001, \eta^{2} p=0.22\right)$ and age $\times$ gender $(\mathrm{F}=3.40, p<0.05$, $\left.\eta^{2} p=0.13\right)$ were observed for the PU test. Both tests showed a significant interaction age $\times$ gender $\times$ countries $\left(p<0.05, \mathrm{~F}=2.70, \eta^{2} p=0.10\right.$ and $\mathrm{F}=2.84, \eta^{2} p=0.11$, respectively for LJ and PU).

In contrast to the previous result of MPA (Figure 2 and Figure 3) which characterized a general improvement (i.e. BB, JS, LJ and PU), statistical analysis (Figure 3) showed a general performance retardation with age growth $(6-10$ years old) in the flexibility test $(\mathrm{ST})$ for both populations among both genders $(\mathrm{F}=38.90, \mathrm{P}<$ $0.001, \eta^{2} p=0.56$ and $\mathrm{F}=38.11, p<0.001, \eta^{2} p=0.22$, respective to the Egyptian and German populations). This retardation was especially observed in $8-10$ age range for girls in both countries $(p<0.001$ and $p<0.01$ and in the $6-8$ age range for German boys $(p<0.01)$. In this test a significant interaction for age $\times$ countries was shown $\left(\mathrm{F}=4.48, p<0.01, \eta^{2} p=0.16\right)$.

\section{Discussion}

The present study had two purposes. The first was to evaluate the anthropometric and motor performance abilities in Egyptian children aged between 6 and 10 years old. Secondly, the study then sought, to compare the anthropometric and motor results from the Egyptian children with those of their German peers looking for differences and suggesting recommendations to improve the content of PE curriculum in both countries. For these reasons the present study assessed three factors for each tested parameter (i.e., difference by countries, gender and age).

Statistical results showed that the country factor significantly affected the anthropometric parameters (i.e. Height, Weight and BMI) (i.e. German children were taller and Egyptian peers have higher weight and BMI). However, the gender factor shows no significant effect in the same parameters and no interaction between these two factors was found. Concerning the MPA, the factors of both countries and gender had a significant effect on children's motor ability with a better performance by the German children in comparison to their Egyptian counterparts for the majority of tested abilities (i.e. JS, PU, LJ and SR). Existence of interaction between countries and gender for these abilities was shown. With maturation (age as a factor), the achievement level for both genders in the two different countries show a positive improvement in the coordination and strength test and reduction in the flexibility test.

German children showed a stable progression and a higher rate of improvement for the majority of motor tests. 
The exception was with respect to the PU test in which Egyptian boys performed better than Egyptian girls. A significant interaction between age $\times$ countries was shown for all tests except for PU in which the interaction was between age $\times$ gender. Likewise, a significant interaction age $\times$ gender $\times$ countries was shown for strength abilities.

It should be noted that the most prominent testing result differences between the German and Egyptian populations (i.e., better results for German) were predominantly observed between 6 - 10 age levels and generally centered on strength testing. The majority of other abilities, there was no difference in regard to specific age; but instead developed as children got older.

For the Egyptian children, these findings suggest deficiency (i) in physical activity before school age, (ii) in the Egyptian physical education curriculum So that some recommendations to improve physical fitness before school age as well while in school are given in the conclusion.

The results of the present study support the conclusions found in previous research which noted that the stage of motor development is not dissimilar for children on a worldwide perspective. The developmental rate is dependent on the special characteristics of the environmental conditions in which the child grows (Barros et al., 2003; Giagazoglou et al., 2007). In fact anthropometric data (i.e. height, weight and BMI) in the present study were affected only by the countries factor while gender factor has no effect. In addition, statistical analysis of the motor abilities development with respect to age show that for both counties children improve coordination and strength abilities and at the same time deteriorate their flexibility; But this change occurs with a different rate of increase which result in a significant interaction between age $\times$ countries and no significant interaction between age $\times$ gender.

Additionally, these present findings confirm the research of Bös et al. (2002) who suggests that the presence of different cultural conditions while growing up as well as physical factors such as body height, body weight and typical diseases could influence the motor development. The present findings are in line with previous research by Kretschmer (2001) \& Bryan et al. (2006) who suggest that the level of MPA is culturally different and that children raised in Western cultures (e.g. German) have a better physical fitness than those growing up in non-Western cultures (e.g. Egypt).

Therefore, body composition and social cultural factors including the educational system, and the rate of physical and motor activities appear to be the most influential factors in reducing the rate of motor development by Egyptian children as compared to German children.

The other factors that could illustrate the superior assessment scores for German children over their Egyptian peers are from the social-cultural conditions which are demonstrated in the range of physical and motor activities existing in both countries. Indeed, the German children have more chances than their Egyptian peers to participate in many well-organized physical and motor activities. Moreover, the socio-cultural factors can be considered as indicators for a positive relationship between motor development and material and social factors that directly affect the possibilities and suggestions for physical activity. These include a large living area, good accessibility of play areas, sports interest of parents, movement-friendly kindergarten or school, and membership in a sports club (Breithecker, 1998; Emrich et al., 2004; Rethorst, 2004; Scheid, 1994a, 1994b).

By analyzing the difference between Egyptian and German PE curriculum, the primary reason stressed for raising the performance level of MPA might be found. MPA, which are energetically based in things such as strength and endurance, are generally absent in Egyptian PE curriculum. For instance, the Egyptian PE curriculum does not include specific activities to develop strength and endurance. This was in direct contrast to the German Children where the direct effect from MPA to strength was 0.97 (Lämmle et al., 2010). Moreover, the fundamental motor skills such as running, jumping and throwing are demonstrated as the main part of German PE curriculum in primary schools. In addition, smaller classes (compared to their Egyptian counterparts) and the large amounts of sport equipment allow the German PE teacher to involve the students in class activities in a much more appropriate and effective manner. Actually, focusing on developing sports skills related to sport performance and reducing the physical and motor activities that provide development of MPA (especially energetically based activities) were clearly at a disadvantage in the context of the Egyptian PE curriculum.

Moreover, in Germany, the variety of playgrounds - considered to be one of the most influential factors of the environment that offer suitable and appropriate places for outdoor physical and motor activities (Daniel, 2007) — can also be an explanation for the high level of motor achievement that exists by the energetic-conditional abilities (especially in long jumping) for German children over their Egyptian peers.

Regarding the differences between boys and girls in the achievement level of motor abilities; the German 
population show that girls perform better in the coordination and flexibility test $(p<0.05)$ while boys prove superiority in the LJ test $(p<0.05)$. In Egypt, testing revealed very different results. Boys had superior scores in the majority of test (i.e. JS, PU and LJ) $(p<0.05)$ while no significant superiority was found in favor of the Egyptian girls $(p>0.05)$.

These findings reflect the situational gender inequality in PE practice and in Egypt. Furthermore, these results confirm previous research which indicated that the inequality between boys and girls in participating PE and sports activities in Middle East countries compared to European countries (Hardman, 2009).

\section{Conclusion}

Although heredity sets the limits of growth and development, environmental factors play an important role in the extent to which these limits are reached. Factors, such as nutrition, exercise, and physical and motor activity, are major considerations affecting growth and development. This is especially true in relation to the complexities of socio-cultural factors and motor development of children, which have still not been researched in great detail. Therefore, more international comparison studies investigating MPA (related to the social-culture factors) and longitudinal studies (as a future basic study) for the Egyptian environment are needed to help better understand the developmental differences.

\section{Recommendations to Improve the Content of PE Curriculum in Both Countries}

Results found in this current study have yielded several recommendations. An intervention program is recommended for Egyptian children focusing on retraining teachers how to install a student endurance program (Sabri et al., 2014) or a supplemental aerobic program (Regaieg et al., 2013), both of which have a significant effect on reducing body weight and BMI values. As well as, considering the gender equality in the implementation of the $\mathrm{PE}$ and sport activities. Furthermore, it is recommended that the Egyptian PE curriculum include more coordination exercises at the primary school age (6 - 10 years old). In addition, improvements in strength ability (Jumping, pushing,) training of Egyptian children from early age ( $<6$ years) are needed besides considering the outdoor activities. Moreover, strength exercises for Egyptian girls age 6 - 8, for German girls age 8 - 10, and German boys age 7 - 9 are also recommended (oriented to the lower limbs for boys and whole body for girls).

\section{References}

Abdel Karim, O. (2013). Motor and Cognitive Development of Selected Egyptian and German Primary School Aged-Chlidren. A Cross Cultural Study, Magdeburg: University of Magdeburg.

Alwasif, N. (2001). Körperliche Aktivität, Fitness und Gesundheit im interkulturellen Vergleich. Eine empirische untersuchung an Ägyptischen und Deutschen Studierenden. Karlsruhe: Universität Karlsruhe.

Barros, K. M., Fragoso, A. G., Oliveira, A. L., Cabral-Filho, J. E., \& Castro, R. M. (2003). Do Environmental Influences Alter Motor Abilities Acquisition? A Comparison among Children from Day-Care Centers and Private Schools. Arquivos de Neuropsiquiatria, 61, 170-175. http://dx.doi.org/10.1590/S0004-282X2003000200002

Booth, M., Macaskill, P., Phongsavan, P., Okeley, T., Patterson, J., Wright, J., Bauman, A., \& Baur, L. (1997). NSW Schools Fitness and Physical Activity Survey. Sydney: NSW Department of Education and Training.

Bös, K. (1987). Handbuch Sportmotorischer Tests. Handbook of Sport-Motor Tests. Göttingen: Hogrefe.

Bös, K. (1992). Sport International-The Relevance of Fitness Tests and Fitness Programs in European Countries—Results from a Questionnaire with Fitness Experts. International Journal of Physical Education, 29, 37-39.

Bös, K. (2003). Motorische Leistungsfähigkeit von Kindern und Jugendlichen. In W. Schmidt, I. Hartmann Tews \& W.-D. Brettschneider (Eds.), Erster Deutscher Kinder- und Jugendsportbericht (pp. 85-107). Schorndorf: Hofmann.

Bös, K. (2009). Deuscher Motorik Test (DMT 6-18). In Motorische Test Für Kinder und Jugendliche (pp. 17). Deutsche Vereinigung Für Sportwissenschaft, ad hoc Ausschuss.

Bös, K., \& Scheid, V. (1994). Grundlagen und Methoden der motorischen Entwicklungsdiagnostik im Kindesalter. In J. Baur, K. Bös, \& R. Singer (Eds.), Motorische Entwicklung Ein Handbuch (pp. 335-355). Schorndorf: Hofmann.

Bös, K., \& Ulmer, J. (2003). Motorische Entwicklung im Kindesalter. Monatsschrift Kinderheilkunde, 151, 14-21.

Bös, K., Opper, E., \& Woll, A. (2002). Fitness in der Grundschule. Förderung von körperlich-sportlicher Aktivität, Haltung und Fitness zum Zwecke der Gesundheitsförderung und Unfallverhütung. Wiesbaden: Bundesarbeitsgemeinschaft für Haltungs- und Bewegungsförderung. 
Breithecker, D. (1998). Erkundungsstudie zur Effizienz des "bewegten Unterrichts". In U. Illi, D. Breithecker, \& S. Mundigler (Hrsg.), Bewegte Schule-Gesunde Schule (pp. 103-116). Zürich: IFB.

Bryan, N. S., Tremblay, M. S., Perez, C. E., Ardern, C. I., \& Katzmarzyk, P. T. (2006). Physical Activity and Ethnicity: Evidence from the Canadian Community Health Survey. Canadian Journal of Public Health, 97, 271-276.

Craig, C., Beaulieu, A., \& Cameron, C. (1994). Data Analysis of Fitness and Performance Capacity. Ottawa: Canadian Fitness and Lifestyle Research Institute.

Daniel, W. (2007). Motorische Leistungsfähigkeiten vor Grundschulkindern. Untersuchung der Einflussfaktoren.

Elbatrawy, A. (2008). Förderung der motorischen Fähigkeiten bei Kindern mit geistiger Behinderung durch Freizeitaktivitäten. Eine Studie an Schulen in Ägypten unter Ausnutzung von Erkenntnissen in Deutschland, Karlsruhe: Universität Karlsruhe.

Emrich, E., Klein, M., Papathanassiou, V., Pitsch, W., Schwarz, M., \& Urhausen, A. (2004). Soziale Determinanten des Freizeit - und Gesundheitsverhaltens saarländischer Schülerinnen und Schüler-Ausgewählte Ergebnisse der IDEFIKSStudie. Deutsche Zeitschriftfür Sportmedizin, 55, 222-231.

Gallahue, D., \& Ozmun, J. (2006). Understanding Motor Development: Infants, Children, Adolescents, Adults (6th ed.). New York: McGraw-Hill.

Giagazoglou, P., Kyparos, A., Fotiadou, E., \& Angelopoulou, N. (2007). The Effect of Residence Area and Mothers Education on Motor Development of Preschool Age Children in Greece. Early Child Development and Car, 177, 479-492.

Hardman, K. (2009). A Review of the Global Situation of Physical Education in Schools. International Journal of Physical Education, 3, 15-16.

Hassan, O. (2003). Evaluation sportartspezifischer konditioneller Fähigkeiten bei Talenten: Ein Vergleich zwischen deutschen und ägyptischen Kunstturn-Talenten im Alter von 10-12 Jahren. Dissertation, Konstanz: Universität Konstanz.

Kambas, A., Antoniou, P., Xanthi, G., Heikenfeld, R., Taxildaris, K., \& Godolias, G. (2004). Unfallverhütung durch Schulung der Bewegungskoordination bei Kindergartenkindern. Deutsche Zeitschrift für Sportmedizin, 55, 44-47.

Kelly, L. (2010). Skill Development and Assessment in Elementary Physical Education. Published Online.

Ketelhut, K., Mohasseb, I., Gericke, C. A., Scheffler, C., \& Ketelhut, R. G. (2005). Verbesserung der Motorik und des kardiovaskulären Risikos durch Sport im frühen Kindesalter. Deutsches Ärzteblatt, 102, A1128-A1136.

Kretschmer, J. (2001). Changes in Childhood and Children's Motor Development. International Journal of Physical Education, 3, 114-126.

Krombholz, H. (2005). Bewegungsförderung im Kindergarten. Ein Modellversuch. Band 152: Beiträge zur Lehre und Forschung der Leibeserziehung. Schorndorf: Hofmann.

Kuntzleman, C. T., \& Reiff, G. G. (1992). The Decline in American Children's Fitness Levels. Research Quarterly for Exercise and Sport, 63, 107-111. http://dx.doi.org/10.1080/02701367.1992.10607567

Kunz, T. (1993). Weniger Unfälle durch Bewegung. Mit Bewegungsspielen gegen Unfälleund Gesundheitsschäden bei Kindergartenkindern. Schorndorf: Hofmann.

Lämmle, L., Tittelbach, S., Oberger, J., Worth, A., \& Bös, K. (2010). A Two-Level Model of Motor Performance Ability. Journal of Exercise Science \& Fitness, 8, 41-49. http://dx.doi.org/10.1016/S1728-869X(10)60006-8

OECD (2001). Lernen Für das Leben. Erste Ergebnisse der internationalen Schulleistungsstudie PISA 2000. Paris: OECD Publications.

Regaieg, S., Charfi, N., Kamoun, M., Ghroubi, S., Rebai, H., Elleuch, H., Feki, M. M., \& Abid, M. (2013). The Effects of an Exercise Training Program on Body Composition and Aerobic Capacity Parameters in Tunisian Obese Children. Indian Journal of Endocrinology and Metabolism, 17, 1040-1045. http://dx.doi.org/10.4103/2230-8210.122619

Rethorst, S. (2004). Kinder in Bewegung. Welche Chancen bieten bewegungsfreundliche Kindergärten für die motorische Entwicklung im Kindesalter? Sportunterricht, 53, 72-78.

Sabri, G. C., Lazhar, Z., Maamer, S., Rachid, S., Zouheir, T., \& Foued, C. (2014). Effects of the Retraining in Endurance on Anthropometric and Metabolic Profiles' Evolution of the Tunisian Obese Pubescent Boys. Journal of Pharmacy and Biological Sciences, 9, 88-92.

Scheid, V. (1994a). Motorische Entwicklung in der mittleren Kindheit. Vom Schuleintritt bis zum Beginn der Pubertät. In J. Baur, K. Bös, \& R. Singer (Hrsg.), Motorische Entwicklung: Ein Handbuch (pp. 276-290). Schorndorf: Hofmann.

Scheid, V. (1994b). Motorische Entwicklung in der mittleren Kindheit. Vom Schuleintritt bis zum Beginn der Pubertät. In J. Baur, K. Bös, \& R. Singer (Hrsg.), Motorische Entwicklung: Ein Handbuch (pp. 276-290). Schorndorf: Hofmann.

Stodden, D. F., Goodway, J. D., Langendorfer, S. J., Roberton, M. A., Rudisill, M. E., Garcia, C., \& Garcia, L. E. (2008). A Developmental Perspective on the Role of Motor Skill Competence in Physical Activity: An Emergent Relationship. Quest, 60, 290-306. http://dx.doi.org/10.1080/00336297.2008.10483582

Tomkinson, G. R. (2004). Secular Trends in Fitness Performance of Australian Children and Adolescents. Ph.D. Thesis, 
Adelaide: School of Health Sciences, Division of Health Sciences, University of South Australia.

Wagner, M. O., Bös, K., Jekauc, D., Karger, C., Mewes, N., Oberger, J., Reimers, A. K., Schlenker, L., Worth, A., \& Woll, A. (2013). Cohort Profile: The Motorik-Modul (MoMo) Longitudinal Study-Physical Fitness and Physical Activity as Determinants of Health Development in German Children and Adolescents. International Journal of Epidemiology, 43, 1410-1416. http://dx.doi.org/10.1093/ije/dyt098

Wagner, M. O., Worth, A., \& Bös, K. (2009). Problems and Ways of Comparing International Fitness Data. International Journal of Physical Education, Meyer \& Meyer Sport, 3, 22-25. 
Scientific Research Publishing (SCIRP) is one of the largest Open Access journal publishers. It is currently publishing more than 200 open access, online, peer-reviewed journals covering a wide range of academic disciplines. SCIRP serves the worldwide academic communities and contributes to the progress and application of science with its publication.

Other selected journals from SCIRP are listed as below. Submit your manuscript to us via either submit@scirp.org or Online Submission Portal.
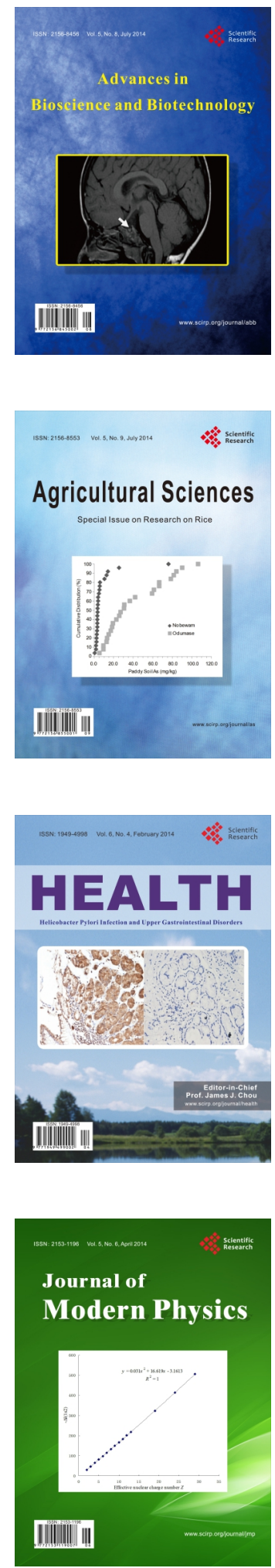
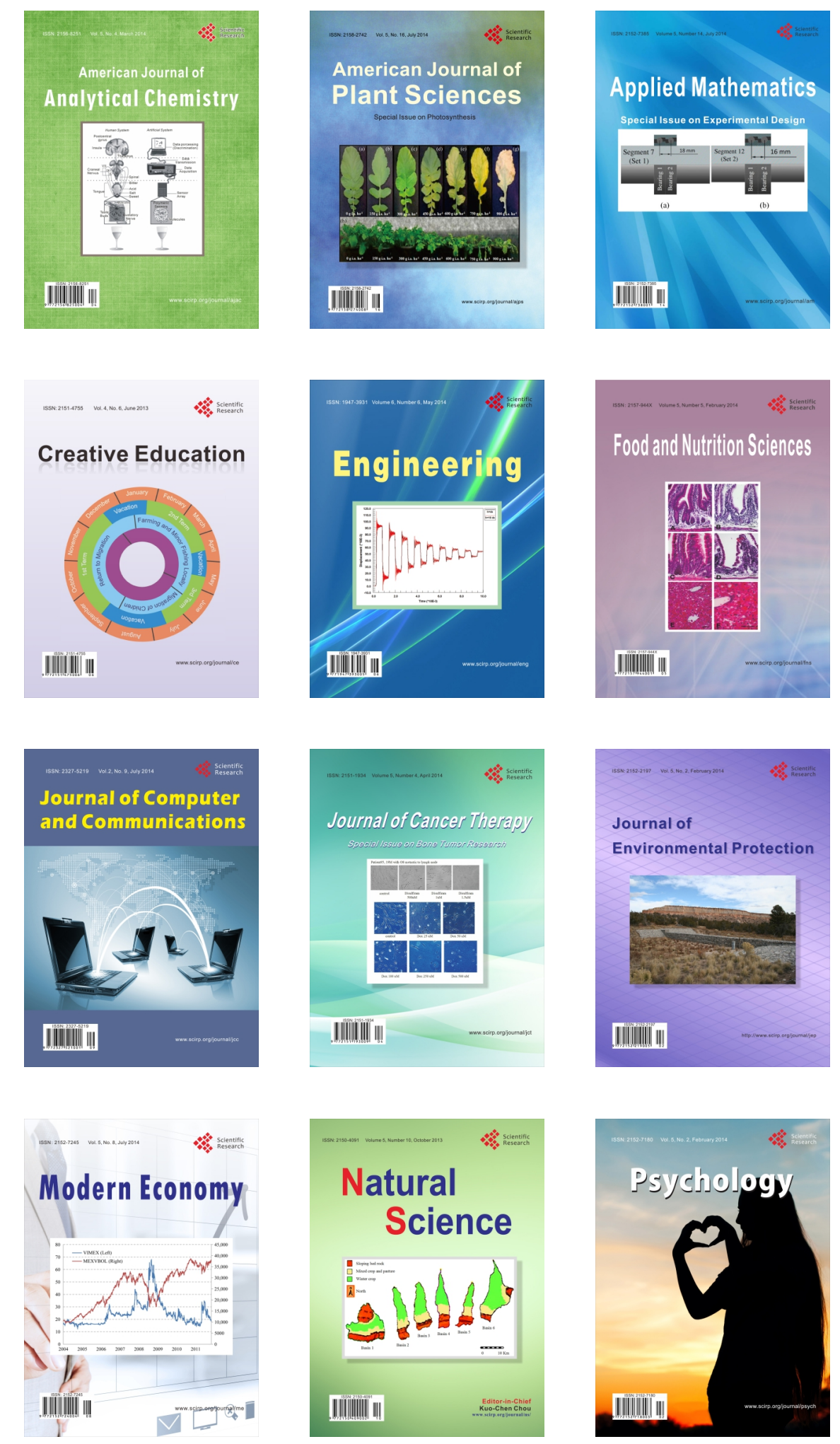